\title{
Functional and Aesthetic Shaping of Kitchen Space and Its Influence on Interpersonal Relations in Households
}

\author{
Przemyslaw Nowakowski ${ }^{1, a,{ }^{*}}$ \\ ${ }^{1}$ Wroclaw University of Technology, Faculty of Architecture \\ Prusa st. 53/55, 50-317 Wroclaw, Poland \\ aprzemyslaw.nowakowski@pwr.edu.pl
}

Keywords: Domestic kitchen, Design, Psychology of architecture.

\begin{abstract}
Providing optimal conditions for work in the kitchen requires a careful functional and aesthetic arrangement. Properly organized workflow may contribute to work ease and safety. Kitchen may also be a place of gathering of household members, or even a place of entertaining guests. Spending time together on preparing meals, dining, etc. fosters integration of the family and tightens relations with friends.

Choosing a particular kitchen model may influence the way of maintaining social and emotional relations between the members of the family. On the other hand, selection of some of the currently popular kitchen layouts may lead to a total isolation of the person preparing meals.

As many household members spend numerous hours in the kitchen, this area of the house needs to be aesthetically pleasing. Creating special mood and atmosphere may improve the attitude and engagement of household members in completion of everyday household chores.
\end{abstract}

\section{Introduction}

Layouts of contemporary European apartments root from the $19^{\text {th }}$ century burgher and tenement houses. After World War I a need for inexpensive housing estates arose, which triggered creation of new design and building trends, such as mass development of rental apartments, which were supposed to have a unified standard and serve practical needs of their users. What is more, a departure from the traditional household model with domestic workers required a different approach to the functional and spatial layout of houses, as, from then on, household chores were performed on one's own.

\section{Functional Kitchens from 1920s}

In 1920s layouts of apartments were analysed basing on everyday needs of household members and graphic diagrams presenting the paths of movement covered while performing the most important chores. Reduction of the number of steps favoured the improvement of work comfort, as well as limitation of the area of apartments, especially the kitchen, where the complex course of work requires a frequent change of place [7].

The author of the first small and functional kitchen was a Viennese architect Margarete Schuette-Lihotzky. In 1926, in Germany, she presented "work kitchen" model, also known as "Frankfurt kitchen" model, which covered the area of $6.5 \mathrm{~m}^{2}$. The size, elongated proportions of the room and placement of two-way galley enabled to considerably shorten the distance covered during performing of the chores and to systematize and organize the order of activities [2]. Meal preparation required merely 
to make a few steps or to turn around. The idea was inspired by small kitchens in Mitropa dining cars.

Creation of proper atmosphere in the "Frankfurt kitchen" was crucial for M. Schuette-Lihotzky. In order to do so the following architectural means were used: regular divisions and proportions of the equipment, various types of lighting and suitable choice of coloring. In order to overcome the narrow perception (width of approx. $190 \mathrm{~cm}$ ) and substantial length of kitchen and to create a pleasant ambiance the following solutions were implemented: slide doors between the kitchen and adjacent room, a wide, horizontal window, which visually widened the room and systems furniture with clear and logical functional divisions [5]. Cabinets were permanently fixed and fitted to the interior, as the furniture popular at that time was too big for the narrow kitchen and it did not fit to the designed functional layout.

A narrow kitchen with a simple layout and parallel kitchen centers was designed to fit only one person. What is more, there was no table around which householders could gather. Margarete Schuette-Lihotzky postulated placing the table in the living room, at a distance not longer than 3 meters from the kitchen [5]. Therefore, both rooms were directly joined by a sliding door (Fig.1). However, in the later built apartments, because of financial reasons, the rooms were not joined together.

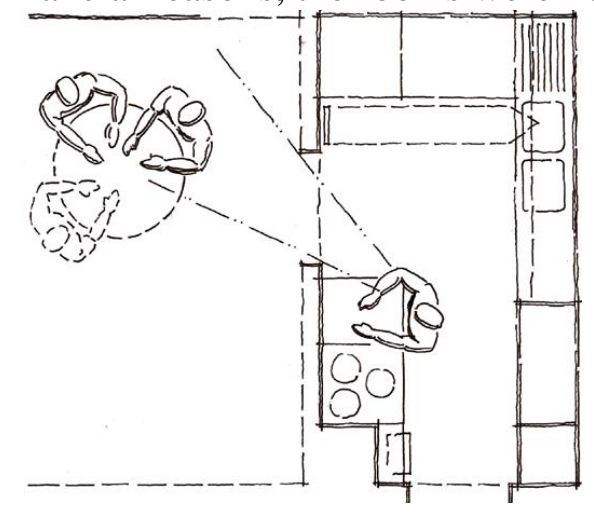

Figure 1. Limited contact between household members in the "Frankfurt" kitchen model (illustration by the author).

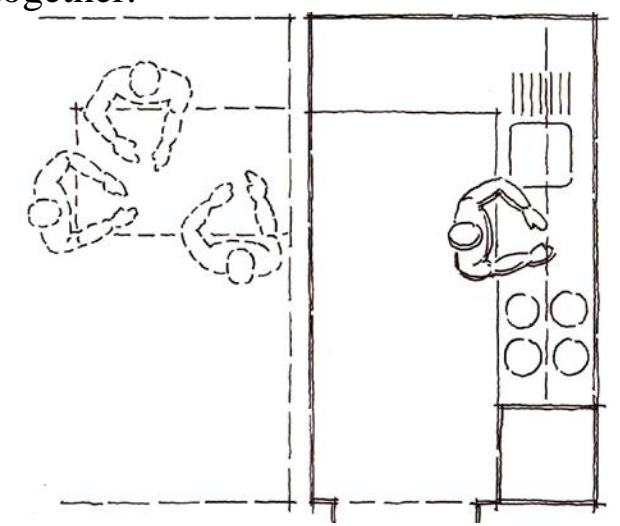

Figure 2. Working in the "work kitchen" while being isolated from other householders (illustration by the author).

At that time, the functional separation of the kitchen and the living room was justified with practical (rationalization of work by limiting the space of rooms and shortening of the covered distances and workflows), technical (gas stove, water pipes with running water, sewage system), as well as hygienic reasons (isolation of waste and smells emerging from the kitchen during meal preparation).

However, shortening of workflow did not result in gaining popularity of the small "Frankfurt" kitchen. Removal of dining area from the "work kitchen" was not accepted by the majority of housewives [5]. Contemporary societies preferred bigger kitchen rooms (with a dining table). It was also then, when a well-known Austrian architect, Adolf Loos, defended a traditional multifunctional kitchen with an area bigger than that proposed in the "work kitchen" model. Loos postulated the importance of social aspects and integration of the family over the ergonomic rationalization of work [8].

Another German designer, Erna Meyer, also criticized the "Frankfurt" model. She believed that it was inappropriate to isolate women working in kitchens and deprive them of a possibility of simultaneous taking care of children playing in other parts of the house. Erna Meyer designed her own model, called the "Munich" kitchen. The room also had a "work" character, nevertheless it was optically and physically connected with the living room through a glass window and door placed on an inside wall. Thanks to this solution it was possible to maintain the contact with other 
household members, in particular with children who were separated from the kitchen dangers [6].

"Frankfurt" kitchen, as well as other similar models, lost its role in the integration of householders and, by doing so, became merely a "work space". The aforementioned model served architects throughout the following decades, especially in multi-family housing. The single function room was meant to be merely a place of preparation of meals, which were supposed to be eaten in the living room. Hence, the separation and the "work kitchen" model led to a total isolation of kitchen chores from other household activities (Fig. 2). On the other hand, the technical solutions introduced back then may be acknowledged as the prototype of later standardization of industrial manufacturing of kitchen equipment.

\section{Work Kitchens in Post-war Houses}

The size and functional layout of an average kitchen in apartments built after World War II may be compared to the "Frankfurt" model. Nevertheless, commonly built "work kitchens" did not gain a considerable popularity in Europe. The need of possessing a dining area in the kitchen was implemented even at the expense of functionality of workflow and work convenience. Therefore, the division of an apartment into separate rooms resulted in duplication of dining areas and placing them both in a separate kitchen, as well as in the living room.

The improvement of economic situation in many countries in 1960s and 70s was reflected in an increase in the standard surface area of apartments. People started to depart from the "work kitchen" model with an isolated work space. Thanks to a bigger surface, the former, multifunctional kitchen model started to be applied more often [2]. Nevertheless, this trend did not result from the willingness to return to the former family structure and the role of an economically non-active housewife; it aimed at giving the possibility of taking part in kitchen chores to all family members. In bigger kitchens it was possible for two people to work at the same time. Moreover, it was easier to place there a small dining table. What is more, built-in furniture and household appliances produced according to normalized standards also gained in popularity.

Back then the kitchen was perceived as a place of fulfilling various needs. An Austrian architecture theorist, Christopher Alexander, in his book A Pattern Language named kitchen the "heart of house" and the place of building of community. Alexander claimed that kitchen should also be a place where household members could spend their time together. He also postulated opening of the kitchen to the remaining part of the house, so that the hostess would be able to spend time with the rest of the family. Christopher Alexander recommended returning to the former functional forms and furniture; he believed that the best furniture was the one originating from folk tradition (e.g. traditional closets and kitchen cabinets). The author also emphasized the importance of the table around which the household members would gather [3].

1970s is the time of more diversified types of furniture and forms of cabinet doors. Former, smooth, white or monochromatic doors were complemented with stylish surfaces with more diverse color palettes and textures. Country kitchens with embellished doors, cornices and furniture profiles became popular. The form density of "work kitchens" was softened by using of, i.a. glass showcases and open cabinets. Therefore, joining the kitchen with the living room did not have to result in a stylistic dissonance between the furniture located in both rooms. Thus, kitchen equipment not only ceased to serve merely a practical function (including cleanness maintenance) but it also gained more esthetical and emotional significance. 


\section{Change of the Kitchen Functional Model in 1980s}

Location of workflows with cabinets along the walls caused the necessity of facing the wall while performing kitchen chores. Also separation of kitchen from the rest of the house increased the isolation from other family members. This issue was risen at the beginning of 1980s by a German designer, Otl Aicher. In his book, Die Kueche zum Kochen: Das Ende einer Architekturdoktrin, the author postulated treating kitchen chores as a "social and communication fostering activity" [1]. Aicher believed that workflow fixed to a wall was a relic of "work kitchen", which hindered relations within the family.

The kitchen model proposed by $\mathrm{O}$. Aicher was a triple row model. The preparation chores were to be performed in a standing position around the work table located in the center of a room. In the middle row there was also space designated for an "island" with a stove. The central location of the table enabled an easy access to all work centers placed along the opposite walls. On one side there was a workflow with the sink, on the other, a workflow with the oven, refrigerator and cabinets used for storage of food products. The layout and size of kitchen enabled participation of others in the preparatory chores (Fig. 3).

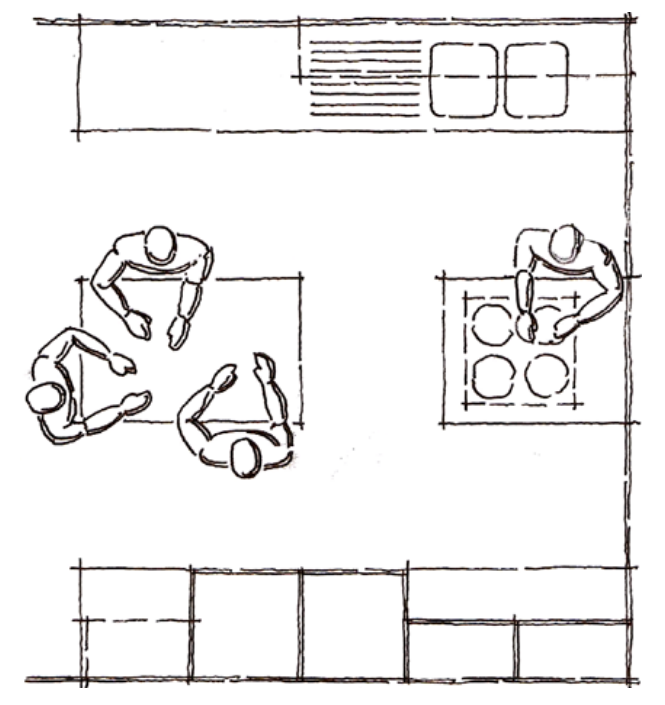

Figure 3. Cooperation in the "island kitchen" by O. Aicher (illustration by the author)

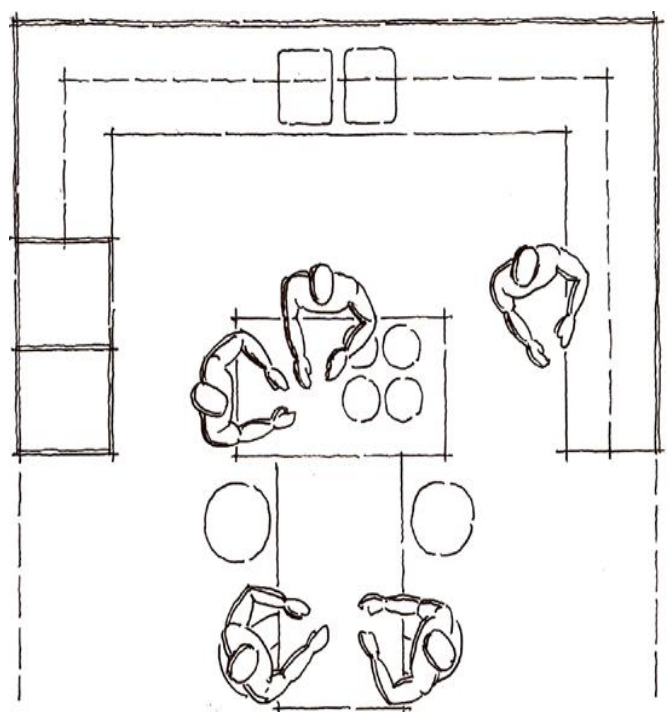

Figure 4. Open plan kitchen and living room with one dining table (illustration by the author)

Otl Aicher believed that preparation and consumption of meals together was an important factor in building relations with others. His design proposals were aiming at encouraging other family members and guests to participate in kitchen chores. The person preparing the meal was supposed to be the "center of everyone's attention" and to be able to maintain eye contact with other household members [1]. The author advised to connect the kitchen with the living room and to introduce professional equipment, which, until then, was used mainly in big industrial kitchens.

The idea of placing the table in the middle of the kitchen was not new, as a similar layout could be found in bourgeois kitchens from the end of $19^{\text {th }}$ century. However, back then, the majority of activities was performed while sitting.

Kitchen with an island and open cabinets proposed by O. Aicher became a model for the following functional and esthetical propositions, especially in bigger apartments. It also contributed to the revival of the idea of a multifunctional kitchen as a central place of home life. Nevertheless, the island layouts were rarely realized, mainly because of lack of space and financial reasons [2]. Despite that, the kitchen table regained its 
meaning, as it served as a place of realization of kitchen chores and eating meals; it was also a place of playing and doing homework, as well as entertaining of guests [4]. As a result, kitchen regained many former functions, which were common to this place in $19^{\text {th }}$ century. However, this turn took place in a technology-rich environment, in kitchens equipped with unified sets of furniture and household appliances.

Introduction of more technologically advanced appliances and furniture encouraged their owners to display them properly (it was the time of introduction of hi-tech style in industrial design). This, in turn, gave rise to the trend of opening kitchens to the representative living room (Fig. 4). What also influenced the gain in popularity of open plan kitchens was diversity of built-in furniture systems and kitchen appliances. This concept became especially popular in smaller apartments, where the space for meal preparation was incorporated into the living room. This solution not only created an impression of more space, but also led to limitation of distances between the rooms. What is more, the table placed in between both zones could become the only dining area in the house.

\section{Summary}

The concept of departure from the multifunctional kitchen model, serving as a crucial center of activity of householders, and assuming the model of space devoted merely to meal preparation emerges as early as 1920s. It is also the time of emphasizing the importance of the functional approach to housing needs and household chores, especially those performed in the kitchen. "Frankfurt" kitchen and following it "work kitchen" were often perceived as models aiming at rationalizing household chores, however, with the sacrifice of values bringing the family together "at the kitchen table". On the other hand, mass development of housing after World War II and, related to it, financial issues were often the cause of lowering the standard of houses in terms of space. The preferred model was "work kitchen", where only one person was able to work at the same time. The kitchen was not treated as a place of integration of the family. It was assumed that family life would take place in other rooms of the house. Also everyday kitchen chores were supposed to be limited to the minimum, as socialist and feminist movements regarded performance of household chores by women as outdated concept of the "bourgeois order" [5]. Despite the aforementioned trends, families preferred to eat their meals next to the place of their preparation. Therefore, the limitation of the surface area of apartments and designing kitchens without a dining area led to the social rejection of the "work kitchen" model, which were heavily criticized especially in 1970s for, among others, "imprisoning" women in cramped spaces and their isolation from the rest of the family [2]. Apartments built in the later period had a bigger surface area and a higher technical standard, that is why it was possible to design kitchens with a more individually selected functional layout and equipment. Currently, a wider offer of apartments enabled to return to the role of the kitchen as a room concentrating the household members, so that even a small kitchen area may have a multifunctional character thanks to spatial connection with the living room.

Considering meal preparation as a pass time and, sometimes, even a way of relaxation has changed the social rank of kitchen in the structure of the apartment, which, in many houses became a prestigious room treated on equal terms with a traditionally understood living room. Nowadays, kitchen may even be perceived as a "kitchen room". Moreover, current designs more and more often enable to accommodate 
several people in the kitchen at once, as well as both planned and spontaneous participation in kitchen chores of household members and even guests.

\section{References}

[1] Aicher O., Die Kueche zum Kochen. Das Ende einer Architekturdoktrin, Callwey Verlag, Munich (1982), pp. 40, 45, 57.

[2] Andritzky M. Oikos. Von der Feuerstelle zur Mikrowelle, Anabas Verlag, Giessen (2000), pp. 14, 104-105, 125.

[3] Alexander Ch., A Pattern Language, Oxford University Press, New York (1977), pp. 671-673.

[4] Flagge I., Geschichte des Wohnens. Von 1945 bis heute, Deutsche VerlagsAnstalt, Stuttgart (1999), pp. 199-262.

[5] Kaehler G., Geschichte des Wohnens 1918 - 1945. Reform, Reaktion, Zerstoerung, Deutsche Verlags-Anstalt, Stuttgart (1999), pp. 266, 277, 280-281.

[6] Meyer E., Der neue Haushalt. Ein Wegweiser zu wirtschaftlicher Hausfuehrung, Franckh'sche Verlagshandlung, Stuttgart (1927), pp. 73, 97, 108.

[7] Petsch J., Eigenheim und gute Stube. Zur Geschichte des buergerlichen Wohnens, DuMont Buchverlag, Koeln (1989), p. 154.

[8] Roth F., Adolf Loos und die Idee des Oekonomischen, Deuticke Verlag, Vienna (1995), p. 195 